\title{
Snow leopard (Panthera uncia) predation and consumption of an adult yak in the Mongolian Altai
}

\section{Miha Krofel, Claudio Groff, Valentina Oberosler, Claudio Augugliaro \& Francesco Rovero}

To cite this article: Miha Krofel, Claudio Groff, Valentina Oberosler, Claudio Augugliaro \& Francesco Rovero (2021) Snow leopard (Panthera uncia) predation and consumption of an adult yak in the Mongolian Altai, Ethology Ecology \& Evolution, 33:6, 636-643, DOI: 10.1080/03949370.2021.1872709

To link to this article: https://doi.org/10.1080/03949370.2021.1872709

\section{Published online: 28 Apr 2021.}

\section{Submit your article to this journal $\widetilde{ }$}

山ll Article views: 118

Q View related articles 5

View Crossmark data $₫$ 


\section{Forum}

\section{Snow leopard (Panthera uncia) predation and consumption of an adult yak in the Mongolian Altai}

Introduction

The snow leopard (Panthera uncia) is an apex predator of mountainous ecosystems in Central Asia, characterised by relatively long feeding times and low kill rates (Johansson et al. 2015; Mallon et al. 2016). Predation is mainly focused on wild ungulates and the vast majority of animals killed by snow leopards are smaller than $100 \mathrm{~kg}$ (Lovari et al. 2013). Throughout most of their range, Siberian ibex (Capra sibirica), blue sheep (Pseudois nayaur), and argali (Ovis ammon) represent the most important prey (Hunter 2015). These species weigh up to $180 \mathrm{~kg}$, which was suggested to be near the maximum limit of the prey size that snow leopard can handle (i.e. about 3 times its size) (e.g. Schaller 1977; Hunter 2015). Accordingly, researchers generally assume that prey like adult yaks (Bos grunniens) with an average body weight of $250 \mathrm{~kg}$ (Bagchi \& Mishra 2006), are too large to be killed by snow leopards (e.g. Devkota et al. 2013; Chetri et al. 2017). In contrast, local livestock herders report that snow leopard can also kill larger prey, including adult yaks (e.g. Li et al. 2013; Suryawanshi et al. 2013), but confirmed records of snow leopard killing prey of this size appear to be lacking in the literature. We also have very limited knowledge about the consumption of snow leopard kills, and the scavengers, including conspecifics, that are using them (Fox \& Chundawat 2016; Schaller 2016). Here we report on a predation event and the following consumption process of a snow leopard kill, a free-roaming adult female yak, which we studied in 2019 using snow tracking, direct observation and camera trapping in the Mongolian Altai.

\section{Methods}

The study was conducted in the Sutai massif (part of the Altai mountain range) in southwestern Mongolia. Elevation in the study area (about $1000 \mathrm{~km}^{2}$ ) ranges between $1800 \mathrm{~m}$ asl in the bottoms of the lowest valleys to the $4226 \mathrm{~m}$ asl at the peak of Mount Sutai. The region has a cold semi-arid climate, with strong winds, long, cold winters and short summers, during which most precipitation falls. Desert-steppe vegetation is predominant with small patches of larch forests on the northern slopes. When the kill was found (20 March 2019) temperatures ranged from $-20^{\circ} \mathrm{C}$ in the morning to $-5^{\circ} \mathrm{C}$ during midday. Sutai massif is located in the northern part of the snow leopard range, where Siberian ibex is the main prey species. 
The kill site was found opportunistically while conducting a camera-trap survey to assess snow leopard abundance and study its ecology. Upon finding the fresh carcass, we inspected the prey remains, skinned the neck section to search for bite marks, determined age of the prey from the tooth wear and used snow tracking in fresh snow to reconstruct the predation event and feeding during the first 2 nights. Thereafter, we used camera-trap data to monitor the consumption process. We set a camera-trap (Reconyx HC500) at the kill site and set it to take pictures in continuous mode.

We manually reviewed all photos and noted the species/individuals present at the kill site, timing of their arrivals and departures, and their behaviour. We used coat patterns to identify different individuals of snow leopards feeding on the carcass and determined their sex based on the presence of scrotum. Location of the kill site and distances to other places reported were determined using handheld GPS (Garmin Oregon).

Results

We found prey remains of an adult yak at 13:30 on 20 March 2019 at the bottom of a high valley at $2623 \mathrm{~m}$ asl, $11 \mathrm{~km}$ northwest from the peak of Mount Sutai (Fig. 1). Prey remains belonged to a female yak, which was estimated to be around 4 years old and weighted approximately $200-250 \mathrm{~kg}$. We observed bite marks on the dorsal and ventral side of the neck. We assume that yak was first grabbed at the nape and then killed by a bite in the throat region. The signs of the first feeding were observed on the lower abdomen anterior to hind leg and on the chest posterior to the front leg (Fig. 1a).

Based on the fresh footprints, we could establish that the yak was killed by a snow leopard and determined that the hunt took place during the previous night (19-20 March). Reconstruction of the hunt suggests that a small herd of yaks was grazing on a steep slope (steepness visually estimated to be around 45 degrees) about $35 \mathrm{~m}$ above the valley bottom. The snow leopard approached the prey from above, moving downhill, and apparently attacked before the yak managed to start running (blood drops were observed at the location of first contact where the yak was grazing). Both animals struggled and fell down the slope to the frozen river at the valley bottom $26 \mathrm{~m}$ below the location of the first contact. The yak was killed on the spot where it fell. We could not establish whether the fall caused any additional injuries to the prey (none were observed on the outside). Footprints of the predator measured $95 \mathrm{~mm}$ in length and $90 \mathrm{~mm}$ in width. No footprints belonging to scavengers were observed on that day.

After feeding, the predator left the kill site and walked for $450 \mathrm{~m}$ up the valley on the frozen river and then turned right to climb up the north-facing slope. We searched with binoculars and found the snow leopard resting on top of the ridge $1 \mathrm{~km}$ from the kill site at approximately $3100 \mathrm{~m}$ asl (https://youtu.be/b304ury4jfs). We also observed three grey wolves (Canis lupus) crossing the valley about $500 \mathrm{~m}$ down the valley and found footprints of a female snow leopard with kitten $1.2 \mathrm{~km}$ from the kill site, but none of them found the carcass according to the snow tracks.

We returned to the kill site the next day (21 March) in the morning and installed the camera trap $4 \mathrm{~m}$ from the carcass (activated at 10:59). We observed from the fresh footprints that the snow leopard returned to the kill the previous night (20-21 March) and was feeding on the meat of the right thigh. We returned to the kill site on June 24 to collect the camera trap. Only dry hide and bones were left from the carcass, which was found at the exact same location.

In total, 10,523 photos were made by the camera trap until batteries were exhausted on 4 April. The images revealed that the predator was a male and returned to feed at his kill three more times after the camera trap was deployed: at 21:58 on 

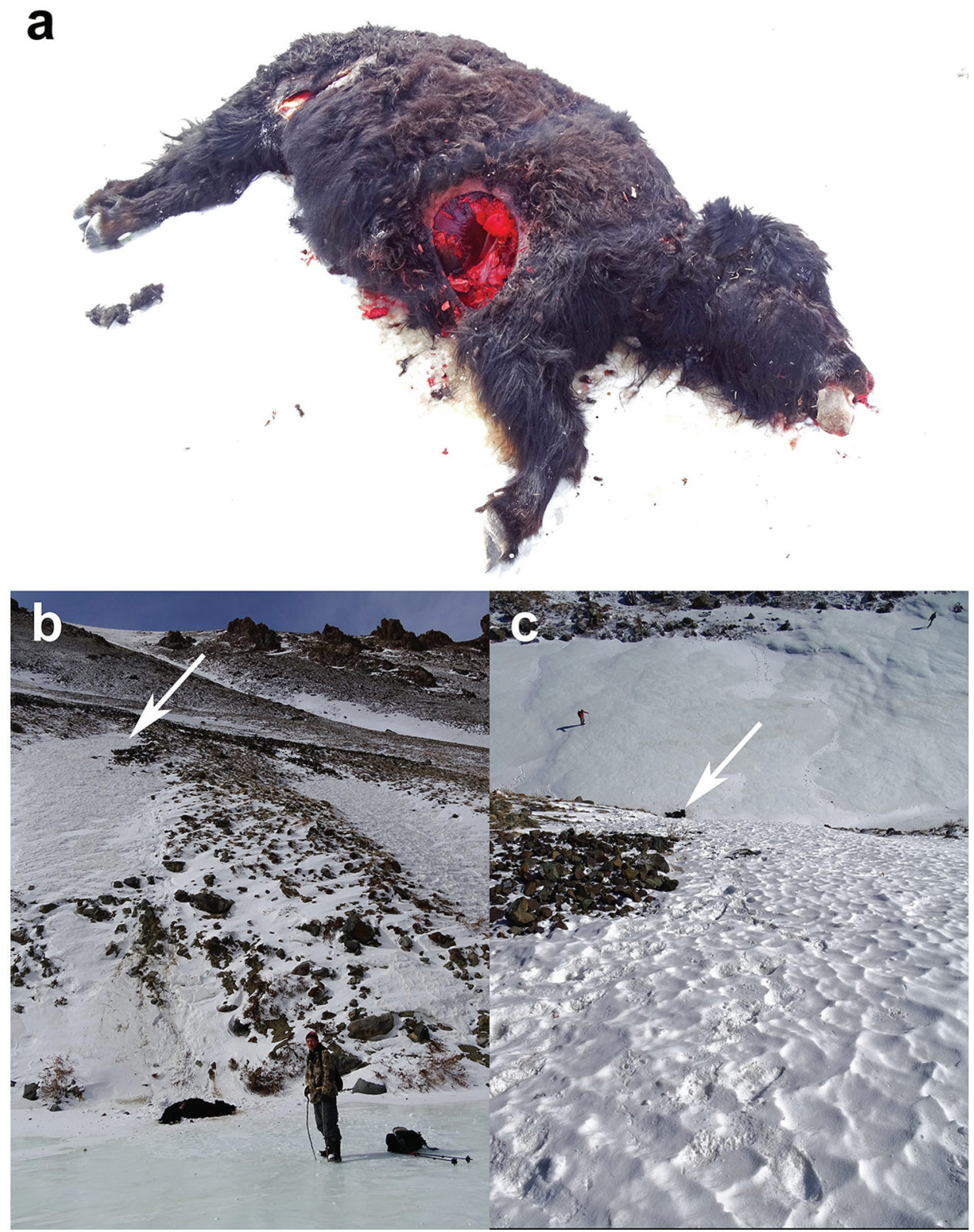

Fig. 1. - (a) Adult female yak killed by a male snow leopard in the Sutai mountain, Mongolia; (b) slope where the hunt took place with arrow indicating the location of the attack; (c) view down the slope from the location of the attack with arrow indicating the carcass. All photos by M. Krofel.

21 March, at 20:21 on 22 March and at 17:01 on 23 March (Fig. 2a). The visits lasted between 55 and $101 \mathrm{~min}$ (mean $=72 \mathrm{~min}$ ) and snow leopard was mostly feeding on the hindquarters, the back, and the flank. During the feeding, he took several breaks and 


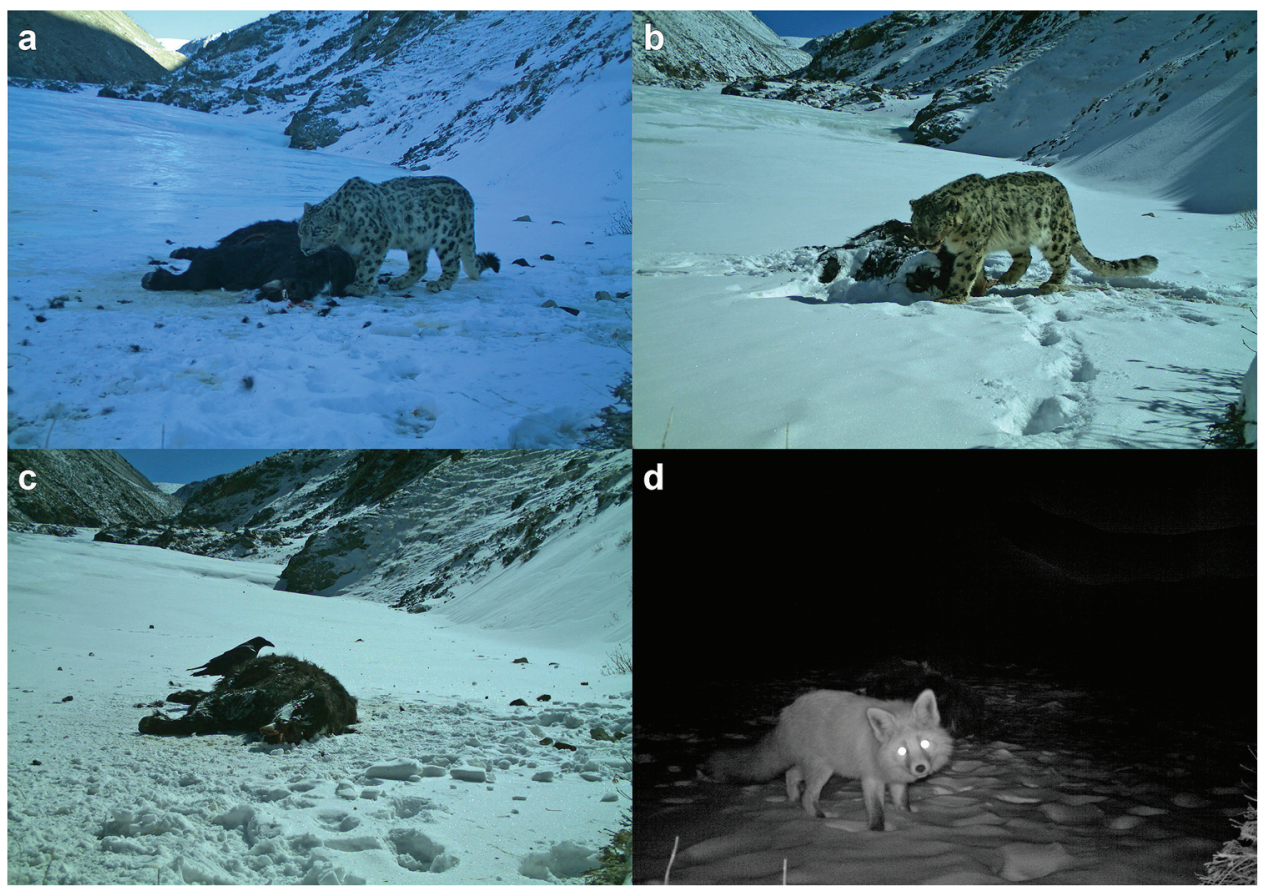

Fig. 2. - Selection of photos recorded by a camera trap set at the kill site in the Sutai mountain, Mongolia: (a) male snow leopard (the predator); (b) the second male snow leopard (the scavenger); (c) common raven; and (d) red fox.

rested by lying on the carcass, but was in total feeding for $96 \%$ of the time spent at the kill site. The predator abandoned the kill 4 days after the predation event (at 18:02 on 23 March) with large quantity of meat remaining on the carcass.

On 27 March at 13:47 a male snow leopard was recorded at the kill site and from the coat pattern we determined to be a different individual (Fig. 2b). He visited the carcass two more times within the next $24 \mathrm{hr}$ (at 18:55 on 27 March and 6:40 on 28 March) and then abandoned the kill site. The second male was feeding on the back, the shoulders, the flank and the hindquarters. The three visits lasted between 36 and $56 \mathrm{~min}$ (mean $=47 \mathrm{~min}$ ) and in total he also spent $96 \%$ of the time feeding.

Besides the snow leopards, two species of scavengers were recorded at the kill site, both also during the period when the predator was still returning to the kill site. On 21 March a common raven (Corvus corax) landed on the carcass and fed for 2 min at the opening on the flank of the carcass (Fig. 2c). A red fox (Vulpes vulpes) was first recorded at the carcass at 22:45 on 22 March and until the end of the camera-monitoring visited the kill site 35 times, on average with 2.7 visits per night with visits lasting between $20 \mathrm{sec}$ and $78 \mathrm{~min}$ (mean $=13.5 \mathrm{~min}$ ). It could not be established whether one or several different foxes visited the carcass, but there was never more than a single animal recorded at the kill site (Fig. 2d). During the first nights, the fox visited the kill site only briefly and without eating, inspecting the carcass and the snow leopard footprints and looking around. Afterwards, the fox was feeding on various parts of the carcass and was recorded several 
times removing (and probably caching) pieces of meat from the kill site. It was also occasionally observed resting by lying on the carcass.

\section{Discussion}

The predation event we report here confirms that snow leopards are capable of killing prey up to 5 times their body weight (adult male snow leopards weight 43-52 kg; Fox \& Chundawat 2016), indicating that even the adults of some of the largest livestock species in their range are vulnerable to predation.

Domestic yaks in the study region are either free-roaming and unattended by owners most of the year (as was the case with the herd attacked) or they are penned each night by the herders. We found several other yak carcasses in the study area with indeterminable cause of death, suggesting that they might represent an important part of the diet of local snow leopard population, which evidently consume yaks, including adults, through both predation and scavenging. Since adult yaks are valuable livestock, their depredation can exacerbate the conflict between the local herders and snow leopards. Such losses can result in retaliatory killing, which is important threat to snow leopards in many parts of their range (McCarthy \& Mallon 2016). Thus we recommend further research on snow leopard-yak interaction, including its effects on human attitudes towards this predator and effectiveness of depredation-prevention measures.

Yaks have been reported to be consumed by snow leopards also in other parts of the species range. For example, yak and cattle (or their hybrids) have been reported to occur in $1.2-14.1 \%$ of the snow leopard scats from India, Nepal and Pakistan (Chundawat \& Rawat 1994; Oli et al. 1994; Bagchi \& Mishra 2006; Anwar et al. 2011). As most of these data originate from scat analyses, it is usually impossible to distinguish between the consumption of a juvenile or adult animal, as well as between predation and scavenging. Inspection of fresh kill sites, as in this study, can overcome these limitations.

Killing technique observed in our case with nape and throat bites following surprise attack from a close distance matches previous observations of snow leopard hunting behaviour (Fox \& Chundawat 1988). Because field conditions did not enable detailed autopsy of the carcass, it remains unclear whether the death was caused by asphyxiation, as is typically assumed (Schaller 1977; Fox \& Chundawat 1988), or whether the predator targeted the carotid artery and the truncus vagosympathicus, which causes immediate death and has been observed in other felids (Krofel et al. 2009).

The parts of the body that were first consumed by the predator are similar to those reported in previous studies on smaller livestock (Schaller 1977; Fox \& Chundawat 1988). Although considerable amount of meat remained on the carcass, the two snow leopards abandoned the carcass after 4 days and 1 day, respectively. Since no other people or any large scavengers have been detected at the kill site, and since the predator returned to feed at the carcass several times also after we left the kill site, we assume that human disturbance was not the cause for abandonment before completed consumption. Possible reasons could be the high availability of food resources in the area and the need to patrol the territory and/or search for females, as the time corresponded with the mating season. It is also possible that either or both of the snow leopards returned to feed on the carcass after our camera monitoring ended due to battery exhaustion.

According to a telemetry study from South Gobi, Mongolia, the kill rates of snow leopards are relatively low (one ungulate kill per 8 days; Johansson et al. 2015), while the time period when snow leopards use their kills and the sequence of feeding bouts 
remain largely unknown. Fox and Chundawat (1988) observed snow leopards feeding on goats for several days close to human settlements, but since their observations were limited to daytime and most of the feeding occurred in dusk and at night, it was not possible to measure the length of the feeding bouts. With the use of a camera trap with invisible infra-red lightning and continuous shooting, we were able to determine that feeding bouts of two snow leopards lasted around $1 \mathrm{hr}$. While the first individual was feeding at dusk and night with only one visit per $24 \mathrm{hr}$, the second individual fed on the carcass also in the midday and returned to feed 3 times within the 24-hr period. Such temporal patterns of snow leopard feeding behaviour indicate that use of prey is similar to other solitary felids preying on ungulates (Krofel et al. 2019) and we recommend camera-trapping as an efficient method to study snow leopard feeding behaviour. We also recommend combination of this method with telemetry and GPS cluster analysis, which enables fast detection of fresh kill sites (Johansson et al. 2015).

Use of remote surveillance of the kill site also enabled us to document scavengers using the prey remains. Scavengers reported previously at snow leopard kills include grey wolf, brown bear, domestic dog, raven, magpie and vultures (Fox \& Chundawat 1988; Hunter 2015). We have very limited knowledge about the role of kleptoparasitism (i.e. the interaction when an animal loses its food to another individual) in snow leopard ecology, although this interaction has been shown to importantly influence several ecological traits among many other solitary felids that hunt large prey (Krofel et al. 2012). This study documented kleptoparasitism at inter- and intra-specific level and we urge further research to understand how it affects the snow leopards, as well as the several species of scavengers that may benefit from their prey remains in this highmountain environment.

Acknowledgements

We would like to thank R. Rizzoli, P. Zorer, B. Barsuren, B. Munkh-Erdene, and T. Yondonjamts for their help with the fieldwork. We are also grateful to B. Munkhtsogt, J. Choikhand, and the administrations of Tsetseg, Darvi soums and Miang Usgalzat National Park for providing logistical support and permits for the fieldwork. We also thank an anonymous reviewer for helpful suggestions.

\section{Disclosure statement}

No potential conflict of interest was reported by the authors.

Funding

Funding was provided by Sabin Snow Leopard grant from the Panthera Corporation, Fondazione Arca/Parco Natura Viva, and Slovenian Research Agency [grants P4-0059 and N10163]. The University of Lausanne provided part of the camera traps. 
Orcid

Miha Krofel (1) http://orcid.org/0000-0002-2010-5219

Valentina Oberosler (1D http://orcid.org/0000-0002-7019-9858

References

Anwar MB, Jackson R, Nadeem MS, Janečka JE, Hussain S, Beg MA, Muhammad G, Qayyum M. 2011. Food habits of the snow leopard Panthera uncia (Schreber, 1775) in Baltistan, Northern Pakistan. Eur J Wildl Res. 57(5):1077-1083. doi:10.1007/ s10344-011-0521-2

Bagchi S, Mishra C. 2006. Living with large carnivores: predation on livestock by the snow leopard (Uncia uncia). J Zool. 268(3):217-224. doi:10.1111/j.1469-7998.2005.00030.x

Chetri M, Odden M, Wegge P. 2017. Snow leopard and Himalayan wolf: food habits and prey selection in the Central Himalayas, Nepal. PLoS ONE. 12(2):e0170549. doi:10.1371/journal.pone. 0170549

Chundawat RS, Rawat GS. 1994. Food habits of snow leopard in Ladakh, India. In: Fox JL, Du J, editors. Proceedings of the 7th International Snow Leopard Symposium. Seattle (DC): International Snow Leopard Trust; p. 127-132.

Devkota BP, Silwal T, Kolejka J. 2013. Prey density and diet of Snow leopard (Uncia uncia) in Shey Phoksundo National Park, Nepal. Appl Ecol Environ Sci. 1:55-60.

Fox JL, Chundawat RS. 1988. Observations of snow leopard stalking, killing, and feeding behavior. Mammalia. 52:137-140.

Fox JL, Chundawat RS. 2016. What is a Snow leopard? Behavior and ecology. In: McCarthy T, Mallon D, editors. Snow leopards. Cambridge (MA): Academic Press; p. 13-21.

Hunter L. 2015. Wild cats of the world. London (UK), New York (NY): Bloomsbury.

Johansson Ö, McCarthy T, Samelius G, Andrén H, Tumursukh L, Mishra C. 2015. Snow leopard predation in a livestock dominated landscape in Mongolia. Biol Conserv. 184:251-258. doi:10.1016/j.biocon.2015.02.003

Krofel M, Kos I, Jerina K. 2012. The noble cats and the big bad scavengers: effects of dominant scavengers on solitary predators. Behav Ecol Sociobiol. 66(9):1297-1304. doi:10.1007/ s00265-012-1384-6

Krofel M, Skrbinšek T, Kljun F, Potočnik H, Kos I. 2009. The killing technique of Eurasian lynx. Belg J Zool. 139:79-80.

Krofel M, Skrbinšek T, Mohorović M. 2019. Using video surveillance to monitor feeding behaviour and kleptoparasitism at Eurasian lynx kill sites. J Vertebr Biol. 68:274-284. doi:10.25225/fozo.037.2019

Li J, Yin H, Wang D, Jiagong Z, Lu Z. 2013. Human-snow leopard conflicts in the Sanjiangyuan region of the Tibetan plateau. Biol Conserv. 166:118-123. doi:10.1016/j.biocon.2013.06.024

Lovari S, Ventimiglia M, Minder I. 2013. Food habits of two leopard species, competition, climate change and upper treeline: a way to the decrease of an endangered species? Ethol Ecol Evol. 25(4):305-318. doi:10.1080/03949370.2013.806362

Mallon D, Harris RB, Wegge P. 2016. Snow leopard prey and diet. In: McCarthy T, Mallon D, editors. Snow leopards. Cambridge (MA): Academic Press; p. 43-55.

McCarthy T, Mallon D. 2016. Snow leopards. Cambridge (MA): Academic Press.

Oli MK, Taylor IR, Rogers ME. 1994. Snow leopard Panthera uncia predation of livestock: an assessment of local perceptions in the Annapurna conservation area, Nepal. Biol Conserv. 68(1):63-68. doi:10.1016/0006-3207(94)90547-9

Schaller GB. 1977. Mountain monarchs. Wild sheep and goats of the Himalaya. Chicago (IL): University of Chicago Press.

Schaller GB. 2016. Foreword. In: McCarthy T, Mallon D, editors. Snow leopards. Cambridge (MA): Academic Press; p. xxiii-xxvii. 
Suryawanshi KR, Bhatnagar YV, Redpath S, Mishra C. 2013. People, predators and perceptions: patterns of livestock depredation by snow leopards and wolves. J Appl Ecol. 50 (3):550-560. doi:10.1111/1365-2664.12061

MiHA KROFEL

Biotechnical Faculty, Department of Forestry, University of Ljubljana, Ljubljana, Slovenia (E-mail: miha.krofel@bf.uni-lj.si).

\section{Claudio Groff}

Autonomous Province of Trento, Forest and Wildlife Department, Large Carnivores Division, Trento, Italy

VAlentina Oberosler

Tropical Biodiversity Section, MUSE - Museo delle Scienze, Trento, Italy

Claudio Augugliaro

Green Initiative NGO, Ulaanbaatar, Mongolia and Department of Ecology and Evolution, University of Lausanne, Lausanne, Switzerland

Francesco Rovero

Tropical Biodiversity Section, MUSE - Museo delle Scienze, Trento, Italy and Department of Biology, University of Florence, Sesto Fiorentino (Florence), Italy 